\title{
Tecnologias de comunicação e interação e envelhecimento humano: a busca da inclusão social pela inclusão digital
}

\author{
Vicente Paulo Alves*, Regina Célia de Oliveira**
}

\section{Resumo}

As tecnologias de informação e comunicação (TICs) podem realizar a inclusão digital da pessoa idosa e consequentemente a sua inclusão social. Assim, essas podem auxiliar os idosos a vencer as possíveis dificuldades de inserção no mundo virtual, visto que abrem as portas para que novas relações sociais sejam criadas, ao mesmo tempo em que transformam suas vidas para melhor. A socialização no mundo virtual pode trazer novos relacionamentos e amizades, ajudar na composição daquilo que se entende por envelhecimento saudável e ativo. Por isso, os idosos não precisam ter medo ou receio de aventurar-se pelo mundo das TICs, como se essas fossem algo direcionado exclusivamente para o público jovem, porque estão cada vez mais se adaptando ao público idoso, seja na busca do conhecimento e da informação, seja no entretenimento e no lazer, estão facilitando suas vidas e possibilitando-Ihes uma maior inserção na sociedade.

Palavras-chave: Envelhecimento humano. Tecnologia educacional. Inclusão digital. Inclusão social.

\section{Introdução}

De acordo com o censo de 2010 (IBGE, 2011), as pessoas com 60 anos ou mais, no Brasil, representam 10,8\% da população, demonstrando que não somos mais um país de jovens, mas que está envelhecendo e que precisa tratar com muita atenção esse novo grupo em ascensão. Podemos considerar um aumento vertiginoso, visto que, entre 1950 e 2025, projeta-se que a população brasileira em geral crescerá cinco vezes, enquanto que a população idosa, nesse mesmo período, aumentará quinze vezes. Se considerarmos que as projeções feitas pela Organização Mundial de Saúde (2002), de que, em 2025, 4\% a 6\% das pessoas envelhecerão com fragilidade e apenas $1 \%$ dos idosos terá algum tipo de dependência mais grave, e, portanto, a grande maioria, ou seja, 95\% da população, ficará mais velha mantendo independência, abre-se uma gama enorme de possibilidades de envolver as pessoas idosas em atividades ligadas ao meio digital e à inclusão social.

* Doutor em Ciências da Religião pela Umesp. Professor e coordenador do Programa de Pós-Graduação Stricto Sensu em Gerontologia na Universidade Católica de Brasília. E-mail: vicente@ucb.br

** Pedagoga. Especialista em Gestão Empresarial e Gestão Estratégica da Comunicação. Professora de Metodologia Científica Semipresencial na Rede de Ensino JK, Brasília.

$\rightarrow$ http://dx.doi.org/10.5335/rbceh.v12i3.6003

Recebido em: 03/11/2015. Aceito em: 30/11/2015. 
O Estatuto do Idoso, estabelecido pela Lei $\mathrm{n}^{\circ} 10.741$, de $1^{\circ}$ de outubro de 2003 (BRASIL, 2003), abriu novas possibilidades de participação do idoso na sociedade, assegurando-lhe vários direitos, dentre eles, o direito à vida, à saúde, à educação, à cultura, ao esporte, ao lazer e ao trabalho (Art. $3^{\circ}$ ). Esses direitos devem ser respeitados conforme "a sua peculiar condição de idade" (Art. 20), sendo supervisionado pelo Poder Público, que "criará oportunidades de acesso do idoso à educação, adequando currículos, metodologias e material didático aos programas educacionais a ele destinados" (Art. 21). Por isso, acreditamos que nada mais justo do que possibilitar aos idosos o acesso às tecnologias da informação e da comunicação (TICs) como o direito à educação, ao relacionamento social, ao lazer, etc. As instituições educacionais são convidadas a realizar cursos especiais voltados para idosos, de tal forma que possam incluir "conteúdo relativo às técnicas de comunicação, computação e demais avanços tecnológicos, para sua integração à vida moderna" (Art. 21, § $1^{\circ}$ ).

Portanto, o desenvolvimento das TICs para as necessidades dos idosos, conforme estabelecido no estatuto, pode contribuir com a inclusão social, algo tão necessário para a compreensão do mundo pelo idoso, de modo que haja possibilidades de educação, lazer, relacionamento social, etc. $\mathrm{O}$ grande desafio que se persegue é vencer o preconceito que ainda paira contra a população idosa em utilizar essas tecnologias. Nesse sentido, considera-se necessário denunciá-lo a todo o momento, para que seja superado e se alcance, em consequência, uma vida mais digna.

A palavra idoso pode trazer consigo um conjunto imenso de conotações pejorativas e maliciosas, porque, em uma sociedade que idolatra a juventude, a beleza e a força física, ser idoso significa estar envolvido em um universo de rejeição, discriminação e exclusão. É justamente esse papel que cumprem as TICs que podem ajudar a abrir um mundo novo, cheio de possibilidades aos idosos, sobretudo em relação à sua inclusão social.

\section{0 interesse dos idosos pela busca de novos conhecimentos}

Segundo informações do Instituto Nacional de Estudos e Pesquisas Educacionais Anísio Teixeira (2012), houve um aumento de $60 \%$ de matrículas de alunos, nos últimos cinco anos, com mais de 60 anos, e $90 \%$ de aumento de pessoas com mais de 49 anos, demonstrando que esse campo está em processo de crescimento. Em outras palavras, pode-se dizer que o interesse pela educação continuada está também acompanhando o processo de envelhecimento da população brasileira. Nesse sentido, há iniciativas que propõem usos das TICs que contemplem a clientela de alunos acima dos 60 anos. A atualidade e a relevância dessas iniciativas se mostram quando se têm notícias de que poucas instituições se dedicam a esse tipo de pesquisa, que envolve idosos, e a utilização do Ambiente Virtual de Aprendizagem (AVA).

No ano de 2008, realizamos uma iniciativa inédita propondo uma pesquisa 
diferente com os idosos, a saber: Tecnologias, ambiente virtual e aprendizagem com pessoas idosas, na perspectiva da qualidade de vida e da (re)descoberta do sentido da vida. A pesquisa foi realizada com cem idosos em Brasília e cem idosos em São Paulo, sob a coordenação da Universidade Católica de Brasília e da Pontifícia Universidade Católica de São Paulo. Inicialmente, foram aplicados questionários com o levantamento das áreas de interesse dos idosos ao pesquisar assuntos na internet. As respostas foram sistematizadas em quatro campos: (1) cidadania, (2) qualidade de vida, (3) produtos e serviços e (4) interação social. Construiu-se um ambiente virtual para oferecer aos idosos um curso de extensão, cujo conteúdo foi justamente os quatro itens categorizados. Convidamos, então, todos os duzentos idosos a participar do curso, mas apenas 65 se interessaram; os demais alegaram uma série de dificuldades, desde o deslocamento até a lan house (ou telecentro) até questões ideológicas ou religiosas, afirmando que se sentiriam constrangidos em participar de um curso fora de suas convicções ou crenças. Os resultados da pesquisa foram publicados por Mincache et al. (2011) e mostraram a importância do AVA como espaço compartilhado por diferentes pessoas e pontos de conexão, por meio da internet, que permite a inserção social dos idosos.

O curso de extensão criado no AVA para os idosos considerou as seguintes características descritas por Santos (2003): a) páginas eletrônicas com hipertextos que agreguem intertextualidade, conexões com outros sites ou documen- tos, intratextualidade, conexões com 0 mesmo documento, multivocalidade, ou seja, reunião da multiplicidade de pontos de vista, navegabilidade, ambiente simples e de fácil acesso e transparência nas informações, mixagem, integração de várias linguagens: sons, textos, imagens dinâmicas e estáticas, gráficos, mapas, multimídia, integração de vários suportes midiáticos; b) comunicação síncrona potencializada em tempo real, bem como a assíncrona, feita a qualquer tempo, uma vez que emissor e receptor não precisam estar no mesmo tempo comunicativo; c) atividades de pesquisa fortalecidas; d) atividades avaliativas realizadas com frequência; e) conexões lúdicas disponibilizadas e incentivadas, com desenhos artísticos e navegações fluidas.

\section{Viver mais é também oportunidade de aprender ainda mais}

Se hoje o ser humano vive mais e a sociedade não sabe o que fazer com essa parcela da população, então, é um bom momento de oferecer novas formas para o envelhecimento saudável. Diante dessa realidade, tornam-se urgentes mudanças na forma de conhecer e/ou aprender "o novo", a fim de contribuir para o desenvolvimento global e harmonioso de quem envelhece. $\mathrm{O}$ antigo paradigma que associa a velhice às representações deficitárias deve mudar para um novo olhar educacional, que preconize a busca da qualidade de vida em todas as idades (BOTH, 2002).

A velhice é uma etapa, provavelmente a mais longa da vida, por isso, viver 
muito e bem é um direito do ser humano. Assim, todos querem viver mais, mas ninguém quer ser velho. Aliás, ter uma vida longa sempre foi a aspiração da humanidade, mas não podemos esquecer que a velhice é caracterizada muito mais pela forma como a sociedade determina e encara o envelhecimento do que pela própria percepção do idoso a respeito desse processo.

$\mathrm{O}$ fato de o idoso viver em um contexto inóspito da sociedade poderá contribuir para aumentar o medo que a maioria tem de envelhecer e, ainda, para a perda do sentido da vida que acompanha muitos idosos. A falta de sentido na vida pode ser percebida quando o nível de frustração existencial é elevado e as pessoas se encontram em um estado de vazio existencial, em que os valores pessoais já não são aceitos pelos mais jovens. O medo da perda do respeito social torna-se um dos maiores inimigos da velhice. A isso, soma-se o fato de que as pessoas idosas perdem o direito de continuarem ativas no trabalho e passam a ser consideradas como estorvos para $o$ trabalho produtivo.

A aprendizagem em ambiente virtual é uma nova modalidade de formação continuada que está ajudando as pessoas a ter uma melhor qualidade de vida, na busca de uma maior consciência do seu mundo vivido e na construção de um sentido da vida. Segundo Kachar (2005), os idosos podem encontrar, nesse ambiente virtual, a oportunidade para atualizarem-se por meio de uma educação continuada, "objetivando ampliar a autonomia e, a comunicação para manter contatos e estabelecer novas relações, amenizando a solidão e as perdas afetivas" (KACHAR, 2005).

A educação a distância intermediada por computador pode ser um meio importante para que os idosos mantenham ativas suas capacidades intelectuais e afetivas, na medida em que permite que esses busquem atualizar seus conhecimentos. Nesse sentido, há uma variedade de sites que podem auxiliar nos mais variados temas, por exemplo: http://www.sitedaterceiraidade.com.br; www.portaldoenvelhecimento.com.br; http://www.aterceiraidade.com, entre outros portais. $\mathrm{O}$ importante é que as interações entre essas pessoas no ambiente resultem em uma interação social, com a noção de compromisso, de sentido da vida e de intercâmbio de valores morais.

A qualidade de vida e as interações entre os sujeitos envolvidos são fatores importantes que interferem no processo educacional dos idosos. Apesar das resistências e até mesmo do "analfabetismo tecnológico" de muitos idosos, há muitas pesquisas que estão sendo pensadas para viabilizar o acesso e a navegação no ambiente virtual, por meio de ações educativas, possibilitando uma aprendizagem acessível que possa responder às necessidades cidadãs das pessoas idosas.

As tecnologias, enquanto artefatos, podem ser exploradas pedagogicamente no ambiente educacional, no entanto, não são educacionais em si mesmas, mas são meios e instrumentos que, por meio de metodologias de ensino e da criação de situações de aprendizagem, podem propiciar a formação e o desenvolvimento do indivíduo. As metodologias de ensino, na mediação por meio do computador, po- 
dem auxiliar os idosos a se descobrirem e encontrarem novas propostas para suas vidas. A diferença não está na tecnologia como artefato, mas na metodologia de ensino pautada por teorias educacionais que propiciam a aprendizagem pelos idosos: para além do aprender sobre o computador, é importante aprender por meio do computador.

Sendo pertinente para o indivíduo que envelhece a questão do "sentido de vida", essa pode ser pensada por meio da educação mediada pelo ambiente tecnológico on-line, de forma que o idoso possa encontrar novos projetos de vida que deem sentido à sua existência.

Os idosos que já utilizam o ambiente virtual ainda encontram dificuldades para lidar com as tecnologias ao interagir com ambientes de ensino a distância. Assim, é preciso construir um ambiente com uma interface amigável e acessível, de acordo com suas condições do envelhecimento, relacionadas aos aspectos biopsicossociais.

\section{A inclusão social dos idosos}

A inclusão social vem ganhando espaço na sociedade à medida que se vai compreendendo melhor a importância de se viver em uma sociedade igualitária e democrática. Incluir significa compreender, fazer parte. E quando relacionamos isso ao envelhecimento, estamos reforçando que é preciso que os idosos façam parte de tudo aquilo que a sociedade faz e usufrui, como o uso das TICs. Os idosos apresentam características que expõem suas dificuldades causadas pelo próprio processo de envelhecimento, como a saída do mercado de trabalho, a perda gradativa do vigor físico e mental, o rompimento dos laços familiares e de amizade, os processos complexos que alimentam o isolamento e a exclusão social.

É preciso ter cuidado em não identificar velhice com deficiência, o que pode levar a uma visão equivocada da velhice como doença ou algo negativo, seja pela sociedade, seja pelos próprios idosos. Infelizmente, durante a história, as pessoas com mais idade eram tidas como improdutivas e, apesar de serem também reconhecidas como representantes da história viva, ficavam escondidas do convívio social. Como escrevia Beauvoir: "[...] para a sociedade a velhice aparece como uma espécie de segredo vergonhoso, do qual é indecente falar" (1990, p. 8).

Sassaki (1997) acredita que a inclusão social é a forma pela qual a sociedade se adapta para poder incluir, em seus sistemas sociais gerais, pessoas com necessidades especiais, e, simultaneamente, essas também se preparam para assumir seus papéis na sociedade. Para o autor, a sociedade precisa passar por uma modificação, sendo preciso que atenda às necessidades de seus membros, assumindo os idosos como parceiros na discussão de problemas e soluções. Assim, entendemos que essa forma de agir também pode ser o caminho para se incluir os idosos na sociedade.

Sassaki (1997) não fala de integração, porque inclusão e integração não significam a mesma coisa. Integração, para ele, é a inserção de uma pessoa com necessidades especiais preparada para conviver na sociedade, ou seja, uma pessoa deverá ser instruída para 
se adaptar ao movimento da sociedade, enquanto que a inclusão é entendida como a modificação da sociedade como pré-requisito para que essas mesmas pessoas possam buscar seu desenvolvimento e exercer a cidadania. Contudo, o autor estabelece que isso não ocorre de um dia para outro, e que a inclusão social é um processo que contribui para a construção de um novo tipo de sociedade mais inclusiva. Isso acontece por meio de transformações nos espaços físicos das cidades, nos meios de transporte, no interior das políticas públicas e na mentalidade de todas as pessoas, sejam elas jovens, adultas ou idosas.

\section{Entendendo a inclusão social pelo seu oposto: a exclusão social}

Percebe-se que o tema é muito complexo, embora seja tão difundido entre as Organizações não Governamentais e na mídia, pois apresenta caminhos e reflexões na tentativa de encontrar soluções que respeitem as pessoas, particularmente os idosos. Faleiros (2006) propõe entender a inclusão social por meio do seu oposto, que é a exclusão social, porque uma está profundamente vinculada à outra.

De acordo com Sposati (2006), a expressão "exclusão social" é usada hoje de forma generalizada, mas nem mesmo entre os especialistas existe unanimidade quanto ao seu sentido. Segundo Martins (2002), ela também pode ser entendida como resultado de uma mudança nos conceitos que procuram explicar a disposição da sociedade em valorizar tudo aquilo que se relaciona com o desen- volvimento capitalista e o consumismo desenfreado, em que as pessoas valem por aquilo que podem comprar ou por bens que podem adquirir. Portanto, mais que definir problemas, a exclusão social é uma expressão de incerteza e insegurança teórica na compreensão dos problemas sociais da sociedade contemporânea diante da pergunta: como conviver com a diferença?

Godoy (2004) relata que o termo inclusão surge na política como forma de pensar o homem moderno, tendo o mundo globalizado como referência, um mundo em que encontramos os que estão dentro e os que estão fora da convivência social. No Brasil, o termo passou a circular em meados dos anos 1980, principalmente por meio de grupos políticos de esquerda brasileira, mas foi a partir do início do novo século que se iniciaram os debates com mais intensidade sobre o tema.

Nogueira (2003) aponta que o século XX foi um tempo de contradições. Foi o século da valorização do trabalho, mas também foi capaz de submetê-lo às pressões técnicas, organizacionais e políticas. Apesar dos avanços nas áreas de educação, saúde, políticas sociais, não se conseguiu avançar em relação aos antigos problemas e, com a chegada do novo milênio, deparamo-nos com grandes índices de analfabetismo, o retorno de doenças consideradas sob controle e, ainda, o combate de algumas doenças intimamente ligadas a fatores sociais, como a questão de saneamento básico e de habitação, além do desrespeito aos direitos sociais e ao envelhecimento populacional. 
As mudanças ocorridas no mundo no final do século XX, como o surgimento de uma nova cultura, o uso de novas tecnologias e estruturas sociais, acabaram por causar a precarização e a instabilidade do trabalho, o aumento do desemprego, a queda do valor da renda e, consequentemente, 0 aprofundamento da pobreza. Pereira (1996) assinala que, no rastro dessas mudanças, o mundo se deparou com o fenômeno contraditório da multiplicação dos direitos e as constantes ameaças à vida humana, tendo entre essas ameaças o aumento da pobreza e da exclusão.

Para sintetizar essa análise, Wanderley expressou que, do ponto de vista epistemológico, "[...] o fenômeno da exclusão é tão vasto que é quase impossível delimitá-lo" (2002, p. 17). Um de seus recortes é considerá-lo como pobreza ou miséria. Essa é, até certo ponto, compreensível, levando-se em conta que a pobreza, hoje, não se expressa apenas pela ausência de renda ou de comida, ela tem novas formas, como também consequências (MARTINS, 2003).

Desse modo, alguns autores expressam a questão da pobreza de maneira diferenciada. Abreu (2001) reafirma que a pobreza cresce e se expande pelo mundo, principalmente se a política econômica adotada pelo país for neoliberal, responsável pela redução de empregos e salários e por restringir os gastos públicos com relação às necessidades sociais. Já Pereira (2001) identifica a pobreza dividindo-a entre pobreza absoluta e pobreza relativa, considerando essa última como um novo tipo de pobreza a qual transcende a pobreza crônica e a mera ausência de renda. Essa é causada pela desigualdade social, que nos últimos tempos vem aumentando cada vez mais o espaço que separa "ricos" e "pobres", entendida como um processo de exclusão social.

Nesse ponto, destaca-se que a grande maioria dos idosos não se preparou durante a vida para o momento da velhice e não conseguiu passar aos familiares a importância da reciprocidade no processo do cuidar: são pobres, excluídos, quando não enxotados pela família, tratados como um peso e um fardo difícil de ser acolhido no seio familiar, na comunidade religiosa e social na qual sempre viveram. A exclusão social dos idosos se une aos elementos materiais (muitas vezes apresentados sob a forma de indicadores monetários) e aos não materiais, ocorrendo, portanto, uma grande injustiça social que não oferece as condições mínimas para que os idosos possam ter o básico para viver com dignidade, como carinho dos familiares, habitação decente, alimentação equilibrada e segurança para poder ir e vir, entre outros requisitos. Demo (2001) chama de excluídos aquelas pessoas que não têm acesso aos direitos, mesmo com a existência de leis que os garantam de forma universal.

A inclusão social é uma extensão da cidadania, porque une as duas pontas do seu exercício: os deveres e os direitos diante do Estado. Ser cidadão é ter acesso ao trabalho, aos serviços sociais, à educação e à alimentação, entre outros (ZICCARDI, 2001). Contudo, a escolha pelo modelo de desenvolvimento econômico neoliberal, que valoriza de forma extrema o mercado, com avanços apenas 
em setores restritos, ampliando a marginalização de alguns setores da sociedade, como os deficientes e os idosos, acabou por causar o aumento do número dos excluídos e o agravamento da pobreza já existente.

Demo (2001) declara que, em termos estruturais, a exclusão é vista como parte integrante de toda manifestação histórica humana. Os modos de excluir apresentam características distintas em cada contexto histórico e privilegiam processos discriminatórios, que podem ser de gênero, de faixa etária, de raça, de mercado, etc. Faleiros (2006) aponta que a inclusão política, que ocorre na esfera do direito, não repara a exclusão socioeconômica, e a relação entre as duas acaba por se manifestar em um movimento histórico diversificado.

Excluir significa, dentre outras coisas, "[...] pôr de lado, abandonar; pôr fora, eliminar" (FERREIRA, 2010, p. 140). Na sociedade contemporânea, os sujeitos excluídos são todos os que se encontram do lado de fora de um contexto, não pertencem a um determinado grupo, não têm mais serventia ou importância e, por isso, são postos fora e eliminados. Assim, a exclusão revela uma sociedade descartável, como coisa sem utilidade, fazendo com que encontremos o indivíduo como refém do medo.

Uma das possibilidades de incluir socialmente os idosos é por intermédio das TICs, as quais representam novas oportunidades para os idosos, que avançam para a ação cidadã e em direção da qualidade de vida. Atualmente, já estão sendo pensados diversos aplicativos para tablets e smartphones que possam auxi- liar os idosos em suas atividades da vida diária bem como no acesso aos serviços e produtos disponibilizados na internet: compras on-line, denúncias de serviços públicos e privados mal prestados, protocolos de reclamações nas agências de defesa dos usuários e consumidores, entre outros serviços, que são realizados por meio de preenchimento de formulários eletrônicos. Ressalta-se que o uso do internet banking pelos idosos está em franco crescimento, à medida que os bancos reforçam os mecanismos de segurança, capacitam os idosos para esse uso e permitem a acessibilidade por meio de letras e números maiores, permitindo uma boa visualização nas telas de computadores, tablets, smartphones e caixas eletrônicos. Há muitas pesquisas que investem em interfaces gráficas mais amigáveis, mais simples e claras para o uso de pessoas com deficiência ou comprometimento visual, como, geralmente, é o caso dos idosos.

Com essa política social de inclusão, pensar é possível afirmar que sociedade, governo e iniciativa privada estão dando novas alternativas para possibilitar que cidadãos e usuários sejam protagonistas da história, considerando principalmente os princípios regidos pelos direitos sociais e pela cidadania. São políticas de inclusão que, longe de serem processos utópicos, são processos que tentam, de alguma forma, reverter ou atenuar os efeitos provocados pelos anos de discriminação, preconceito e marginalização que os idosos passaram, na época em que o envelhecer era visto de forma negativa pela sociedade [...] e não uma celebração da vitória do avanço científico e tecnológico que a civilização alcançou. 


\section{Considerações finais}

Ao analisar os dados encontrados na pesquisa realizada em 2008, por meio da aplicação do questionário e das entrevistas realizadas, percebeu-se que a qualidade de vida está associada ao uso da internet para um grande número de idosos. Para alguns (8\%), sua qualidade de vida dependeria extremamente do acesso às informações disponibilizadas na internet (MINCACHE et al., 2011). Ou seja, parece que os idosos começam a valorizá-la à medida que melhoram suas vidas, sentem-se incentivados à prática de exercícios físicos, a comer de forma balanceada e a manter um relacionamento afetivo com amigos e familiares.

Os dados do estudo são significativos para o atual crescimento do uso da internet e reforçam a necessidade de democratizar esse acesso para todos, apesar dos elevados custos dos equipamentos e da escolaridade mínima que é requerida para o uso dessa ferramenta. A expectativa é de que esses dados não constituam uma barreira para o aprofundamento das questões que envolvem o idoso e o uso da internet, mas que os seus interesses possam ainda permanecer latentes, $\mathrm{e}$ que se traga um maior nível de qualidade de vida para um grupo significativo de usuários, como o dos idosos.

Um desafio que surge desse estudo é o de envolver os idosos em atividades que realmente façam sentido para eles, que os motivem para uma aprendizagem significativa, aproximando-os das pessoas que amam ou querem bem, como seus familiares e amigos, por meio de ferramentas de comunicação e de diá- logo, pois os idosos não se conformam em serem excluídos digitalmente ou serem tratados como "pessoas alheias" ao processo evolutivo da tecnologia. Eles querem participar e se envolver nesse sistema fantástico que é o da busca pelo conhecimento.

Se as pessoas idosas sentem-se excluídas do mundo digital, com dificuldades em se afirmar e se posicionar frente a essas novas práticas culturais no ciberespaço, então, é o momento de realizar grandes avanços na introdução dos idosos nas TICs. As pesquisas estão constatando o interesse dos idosos em fazer parte das redes sociais, nas quais ocorrem as interações sociais com outras pessoas, principalmente aquelas do grupo de relacionamento, como a família, os amigos, os vizinhos e conhecidos. Se, por um lado, na atual rotina da sociedade, as pessoas têm cada vez menos tempo para as interações, por outro, vem crescendo o uso das ferramentas de comunicação mediada pela internet, que poderiam representar um grande esforço para criar novas redes de apoio social.

Desse modo, as pessoas acabam buscando novas alternativas de socialização. Com cada vez mais recursos, as TICs representam o espaço e a capacidade de alteração nos meios e tipos de interação social, fazendo com que o modo como as pessoas se relacionam também se modifique. A tecnologia pode dar uma contribuição significativa para a interação entre as pessoas, principalmente no caso dos idosos, que frequentemente apresentam a mobilidade reduzida em função de problemas de saúde ou por questões de insegurança das cidades. 
Essa interação somente é possível pela facilidade disponibilizada pelas novas tecnologias em adotar meios de comunicação síncronos ou assíncronos que viabilizam a aproximação com amigos e familiares. Assim, o público mais velho não somente poderá receber notícias, como também comunicar-se, o que fará com que os idosos se sintam parte da vida das pessoas que amam, mesmo estando distantes. Portanto, embora muitos idosos vejam nas TICs como algo de difícil aprendizagem e fora de suas condições e habilidades, eles podem, frente a um problema, como a distância de um ente querido, sentirem-se desafiados e, por meio da superação, começar a fazer o uso delas.

Os idosos buscam nessas novas tecnologias a possibilidade de se reinserir na sociedade e nos grupos de relacionamentos. Ao compreender seu funcionamento, eles criam subsídios que servem de assunto para futuras interações com amigos e familiares, sendo uma das maneiras de estar presente no mesmo universo que seus filhos, netos e sobrinhos, participando da nova sociedade midiática.

Assim, para que a pessoa idosa interaja de forma integral com o meio social em que vive, espera-se que esse público faça parte do processo de inclusão digital, uma realidade hoje, de modo que possa explorar também novas formas de entretenimento e lazer, que contribuam para sua saída da exclusão social e tragam benefícios para a vida social e familiar desses indivíduos, na busca de um envelhecimento saudável e ativo.

\section{Communication technologies and interaction and human aging: the pursuit of social inclusion through digital inclusion}

\section{Abstract}

Information and Communication Technologies (ICTs) can realize the digital inclusion of the elderly and consequently their social inclusion. They are an aid to the elderly to overcome the possible integration difficulties in the virtual world, when you open the door for new social relations are created, while transforming their lives for the better. Socialization in this virtual world can bring new relationships and friendships, help in the composition of what is meant by healthy and active aging. Thus, the elderly need not fear or fear of venturing into the world of ICTs, as something directed exclusively to young people, because they are increasingly adapting to them, is the pursuit of knowledge and information, either in entertainment and leisure, making their lives and allowing them a greater role in society.

Keywords: Human aging. Educational technology. Digital inclusion. Social inclusion.

\section{Referências}

ABREU, M. M. Assistência social e conquista dos direitos sociais: elementos para uma problematização. Universidade e Sociedade, Brasília, v. 11, n. 25, p. 70-78, 2001.

BEAUVOIR, S. A velhice. 3. ed. Rio de Janeiro: Nova Fronteira, 1990.

BOTH, A. Longevidade e educação: fundamentos e prática. In: FREITAS, E. V.; PY, L. (Org.). Tratado de geriatria e gerontologia. Rio de Janeiro: Guanabara Koogan, 2002. p. 1110-1118. 
BRASIL. Lei $n^{\circ} 10.741$, de $1^{\circ}$ de outubro de 2003. Estatuto do Idoso. Brasília: Senado Federal, 2003.

DEMO, P. Exclusão social: novas e velhas formas. Debates Sociais, Rio de Janeiro, n. 58, p. 7-74, 2001.

FALEIROS, V. P. Inclusão social e cidadania. In: CONFERENCIA INTERNACIONAL DE BEM-ESTAR SOCIAL DO ICSW/CBCISS, 32, 2006, Brasília. Anais... Brasília: CBCISS, 2006. Disponível em: http://www.icsw.org/ images/docs/Events/2006_Brazil/17_07_PDF/ vicente_faleiros.pdf. Acesso em: 20 jul. 2014 FERREIRA, A. B. H. Dicionário Aurélio da língua portuguesa. 5. ed. Curitiba: Positivo, 2010.

GODOY, H. C. A noção da inclusão na topologia. In: MELLO, M. M. F.; RESENDE, G. A. Ética da inclusão. Belo Horizonte: Armazém de Ideias, 2004. p. 11-17.

INSTITUTO BRASILEIRO DE GEOGRAFIA E ESTATÍSTICA. Sinopse do Censo Demográfico 2010. 2011. Disponível em: <http:// www.ibge.gov.br/home/estatistica/populacao/ censo2010/sinopse/default_sinopse.shtm>. Acesso em: 10 jan. 2014.

INSTITUTO NACIONAL DE ESTUDOS E PESQUISAS EDUCACIONAIS ANÍSIO TEIXEIRA. Anuário brasileiro de educação básica 2012. São Paulo: Moderna, 2012. Disponível em: <http://www.moderna.com. br/lumis/portal/file/fileDownload.jsp?fileId= 8A8A8A83376FC2C9013776334AAE47F0>. Acesso em: 6 ago. 2014.

KACHAR, V. Internet, um território sem fronteiras para a terceira idade. Portal do Envelhecimento, 2005. Disponível em: <http:// portaldoenvelhecimento.com/old/acervo/ pforum/evve3.htm>. Acesso em: 6 ago. 2014. MARTINS, J. S. A sociedade vista do abismo: novos estudos sobre exclusão, pobreza e classes sociais. Petrópolis: Vozes, 2002.

. Exclusão social e a nova desigualdade. 2. ed. São Paulo: Paulus, 2003.

MINCACHE, G. B. et al. Aliando tecnologia da aprendizagem à qualidade de vida dos ido- sos. Redes.com - Revista de Estudios para el Desarrollo Social de la Comunicación, Sevilla, n. 6, p. 291-299, 2011. Disponível em: <http:// repositorio.unb.br/bitstream/10482/11759/1/ ARTIGO_AliandoTecnologiaAprendizagem. PDF $>$. Acesso em: 20 ago. 2014.

NOGUEIRA, M. A. O século dos paradoxos e a reposição do marxismo. In: AGGIO, A.; LAHUERTA, M. (Org.). Pensar o século XX: problemas e história nacional da América Latina. São Paulo: Unesp, 2003. p. 27-68.

ORGANIZAÇÃO MUNDIAL DE SAÚDE. Active Ageing: a policy framework. Geneva: WHO, 2002.

PEREIRA, P. A. P. A assistência social na perspectiva dos direitos: crítica aos padrões dominantes de proteção aos pobres no Brasil. Brasília: Thesaurus, 1996.

Sobre a política de assistência social no Brasil. In: BRAVO, M. I. S.; PEREIRA, P. A. P. (Org.). Política social e democracia. São Paulo: Cortez; FSS-Uerj, 2001. p. 217-233.

SANTOS, E. O. Ambientes virtuais de aprendizagem: por autorias livres, plurais e gratuitas. Revista da FAEEBA - Educação e Contemporaneidade, Salvador, v. 12, n. 18, p. 425-436, 2003.

SASSAKI, R. K. Inclusão: construindo uma sociedade para todos. Rio de Janeiro: WVA, 1997.

SPOSATI, A. A pobreza e desigualdade no século do desperdício. In: CONFERÊNCIA INTERNACIONAL DE BEM-ESTAR SOCIAL DO ICSW/CBCISS, 32, 2006, Brasília. Anais... Brasília: CBCISS, 2006. Disponível em: http://www.icsw.org/images/docs/ Events/2006_Brazil/17_07_PDF/aldaiza_sposati.pdf Acesso em: 20 jul. 2014.

WANDERLEY, M. B. Refletindo sobre a noção de exclusão. In: SAWAIA, B. (Org.). As artimanhas da exclusão: análise psicossocial e ética da desigualdade social. Petrópolis: Vozes, 2002. p. 16-26.

ZICCARDI, A. Pobreza, desigualdad social $y$ ciudadania: los limites de las políticas sociales em America Latina. Buenos Aires: Clasco, 2001. 